\title{
Measurement of absorption with a p-u sound intensity probe in an impedance tube
}

\author{
Liu, Yang; Jacobsen, Finn
}

Published in:

Acoustical Society of America. Journal

Link to article, DOI:

10.1121/1.2010387

Publication date:

2005

Document Version

Publisher's PDF, also known as Version of record

Link back to DTU Orbit

Citation (APA):

Liu, Y., \& Jacobsen, F. (2005). Measurement of absorption with a p-u sound intensity probe in an impedance tube. Acoustical Society of America. Journal, 118(4), 2117-2120. https://doi.org/10.1121/1.2010387

\section{General rights}

Copyright and moral rights for the publications made accessible in the public portal are retained by the authors and/or other copyright owners and it is a condition of accessing publications that users recognise and abide by the legal requirements associated with these rights.

- Users may download and print one copy of any publication from the public portal for the purpose of private study or research.

- You may not further distribute the material or use it for any profit-making activity or commercial gain

- You may freely distribute the URL identifying the publication in the public portal

If you believe that this document breaches copyright please contact us providing details, and we will remove access to the work immediately and investigate your claim 


\title{
LETTERS TO THE EDITOR
}

This Letters section is for publishing (a) brief acoustical research or applied acoustical reports, (b) comments on articles or letters previously published in this Journal, and (c) a reply by the article author to criticism by the Letter author in (b). Extensive reports should be submitted as articles, not in a letter series. Letters are peer-reviewed on the same basis as articles, but usually require less review time before acceptance. Letters cannot exceed four printed pages (approximately 3000-4000 words) including figures, tables, references, and a required abstract of about 100 words.

\section{Measurement of absorption with a $p$ - $u$ sound intensity probe in an impedance tube $(L)$}

\author{
Yang Liu ${ }^{a)}$ and Finn Jacobsen ${ }^{\text {b) }}$ \\ Acoustic Technology, Ørsted $\bullet$ DTU, Technical University of Denmark, Building 352, \\ Ørsteds Plads, DK-2800 Kgs. Lyngby, Denmark
}

(Received 28 January 2005; revised 4 July 2005; accepted 5 July 2005)

\begin{abstract}
An alternative method of measuring the normal-incidence sound absorption of a sample of material in an impedance tube is examined. The method is based on measurement of the sound pressure and the normal component of the particle velocity using a " $p-u$ " sound intensity probe. This technique is compared with the traditional, well-established "transfer function method" based on two pressure microphones. The results suggest that the new method can be as accurate as the established method, but whereas the influence of transducer mismatch on the transfer function method can be eliminated using a simple "sensor-switching technique," the method based on a $p-u$ intensity probe relies on accurate calibration of the probe. (C) 2005 Acoustical Society of America. [DOI: 10.1121/1.2010387]
\end{abstract}

PACS number(s): 43.20.Ye, 43.58.Bh, 43.58.Fm [AJZ] Pages: 2117-2120

\section{INTRODUCTION}

There are two well-established methods of measuring normal-incidence absorption coefficients and other properties in an impedance tube terminated by a sample of the material under test: the traditional method based on measuring the standing wave ratio frequency by frequency, and the method based on two pressure microphones and excitation with a broadband signal. An early version of the latter method involving measurement of the cross spectrum and the auto spectra of the two microphone signals was proposed by Seybert and Ross in 1977. 'However, the "two-microphone" method in prevailing use was developed by Chung and Blaser a few years later. ${ }^{2}$ This method is known as the "transfer function method" since it involves measuring the transfer function between the two microphone signals. ${ }^{2}$ Both the traditional standing wave method and the transfer function method are standardized, ${ }^{3,4}$ but the transfer function method is much faster and more convenient than the standing wave method. Its errors and limitations have been analyzed by several authors. 5,6

A particle velocity transducer called the "Microflown" has recently become available, ${ }^{7}$ and various " $p-u$ " sound intensity probes based on combining this transducer with a small pressure microphone are now in production. ${ }^{8}$ Our purpose with this note is to examine an alternative to the transfer

\footnotetext{
a) Electronic mail: gordan69@163.com

b) Author to whom correspondence should be addressed; electronic mail: fja@oersted.dtu.dk
}

function method, based on measuring the sound pressure and the particle velocity at a point in the impedance tube using a Microflown sound intensity probe.

\section{OUTLINE OF THEORY}

The sound field in the tube consists of an incident plane wave and a reflected plane wave. The transfer function method is based on ${ }^{2}$

$$
R=\frac{H_{12}-e^{-j k s}}{e^{j k s}-H_{12}} e^{j 2 k l}
$$

where $R$ is the ratio of the sound pressure of the reflected wave to the sound pressure of the incident wave at the termination (at $x=0$ ), $H_{12}$ is the transfer function between the two microphone signals, $k$ is the wave number, $s$ is the distance between the microphones, and $l$ is the distance between the material under test and microphone No. 1. The absorption coefficient of the termination is

$$
\alpha=1-|R|^{2} .
$$

The method based on measuring the pressure and the particle velocity is even simpler. Since the sound pressure is

$$
p=p_{i}\left(e^{j k l}+R e^{-j k l}\right),
$$

and the particle velocity is 


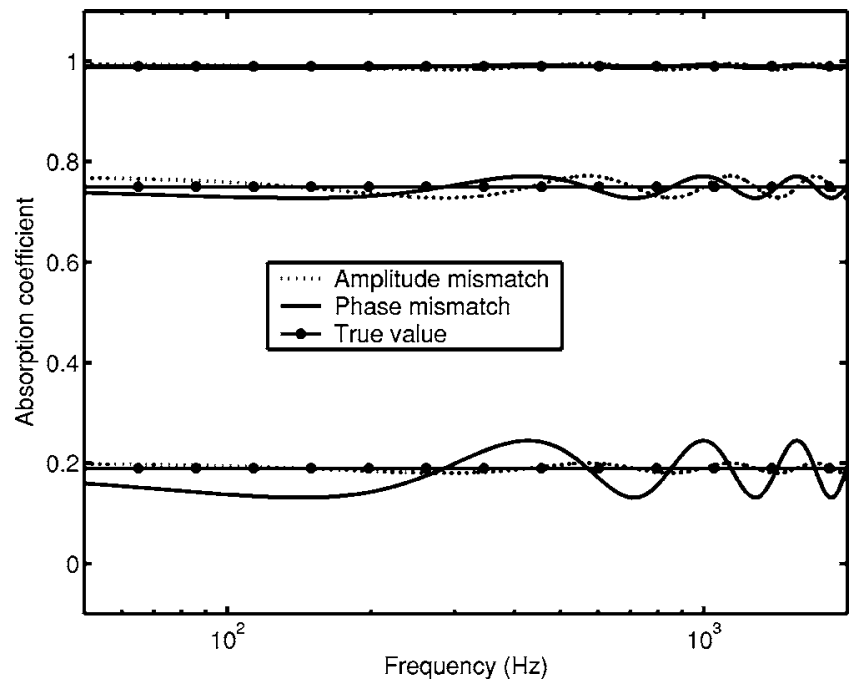

FIG. 1. Estimated absorption coefficient with an amplitude error of $0.5 \mathrm{~dB}$ and with a phase error of $2^{\circ}$, calculated assuming a "true" reflection factor of $0.1,0.5$, and 0.9 , with $l=30 \mathrm{~cm}$.

$$
u_{x}=\frac{p_{i}}{\rho c}\left(e^{j k l}-R e^{-j k l}\right)
$$

where $\rho c$ is the characteristic impedance of air, it follows that the reflection factor is

$$
R=\frac{1-\rho c H_{p u}}{1+\rho c H_{p u}} e^{j 2 k l},
$$

where $H_{p u}$ is the transfer function from the sound pressure to the particle velocity.

In principle both methods require well-matched transducers. However, in practice amplitude and phase mismatch between the two pressure microphones used in the transfer function method are eliminated by the "sensor-switching technique" suggested by Chung and Blaser. ${ }^{2}$ This technique involves measuring the transfer function twice, the second time with the microphones interchanged. Unfortunately, there is no similar simple technique for removing mismatch between the pressure and the velocity transducer; it is necessary to calibrate the device very carefully.

\section{ERRORS AND LIMITATIONS}

In practice one must allow for small residual calibration errors of the $p-u$ intensity probe. Uncompensated residual amplitude and phase mismatch means that $H_{p u}$ becomes $H_{p u}(1+\varepsilon) e^{j \varphi_{e}}$, where $\varepsilon$ is the fractional amplitude error and $\varphi_{e}$ is the phase error. The estimated reflection factor now becomes

$$
\hat{R}=\frac{1-\rho c H_{p u}(1+\varepsilon) e^{j \varphi_{e}}}{1+\rho c H_{p u}(1+\varepsilon) e^{j \varphi_{e}}} e^{j 2 k l},
$$

where

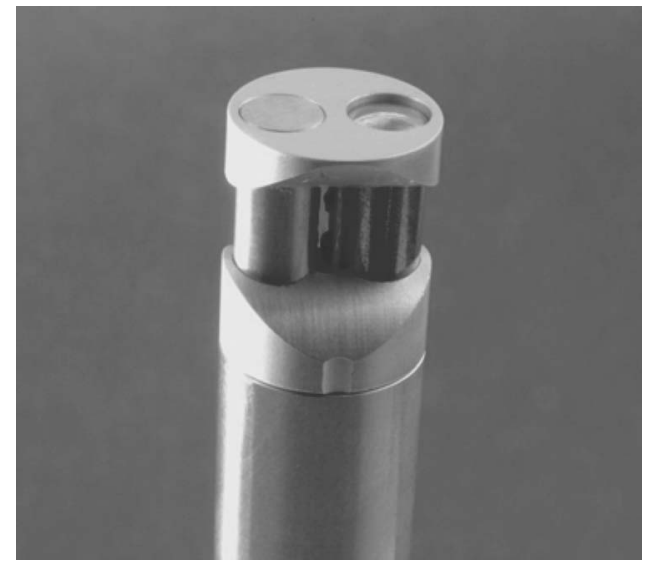

FIG. 2. The Microflown $\frac{1}{2}$-in. sound intensity probe.

$$
H_{p u}=\frac{e^{j k l}-R e^{-j k l}}{e^{j k l}+R e^{-j k l}} .
$$

Figure 1 shows estimated absorption coefficients calculated with an amplitude error of $0.5 \mathrm{~dB}$ and a phase error of $2^{\circ}$ for three different values of the "true" reflection factor $R$, $0.1,0.5$, and 0.9. Obviously the error depends on $k l$. A more interesting observation is that phase mismatch is more serious than amplitude mismatch, and that both errors are much more critical if the sample under test is strongly reflecting. (The various sources of error in the transfer function method also have a more serious influence when the sample under test is strongly reflecting. ${ }^{6}$ ) It is not easy to calibrate the velocity channel of the $p-u$ probe with smaller errors than $0.5 \mathrm{~dB}$ and $2^{\circ} .9$

\section{EXPERIMENTAL RESULTS}

In order to compare the new method with the established transfer function method some experiments have been carried out in an aluminum tube of quadratic cross section with dimensions $7 \times 7 \mathrm{~cm}$ excited by a loudspeaker driven with random noise and terminated by various samples of materials at the other end. Since the mounting of the sample under test is of critical importance for the accuracy of any tube method of measuring absorption ${ }^{10}$ the two measurements took place immediately after each other without remounting the sample. The two pressure signals needed for the transfer function method were measured with two Brüel \& Kjær (BK) microphones of type 4192, and the pressure and particle velocity signals needed for the alternative method were measured using a Microflown $\frac{1}{2}$-in. $p$ - $u$ sound intensity probe. This device measures the sound pressure and the particle velocity component in a direction perpendicular to the axis of the transducer; see Fig. 2. A BK "Pulse" analyzer of type 3560 in the FFT mode was used for all the measurements; postprocessing of the measured frequency responses was done using MATLAB. The first mode of higher order can propagate in tube above $2.4 \mathrm{kHz}$; therefore the frequency range was limited to $2 \mathrm{kHz}$. Before the measurements took place the Microflown velocity channel was calibrated relative to the pres- 

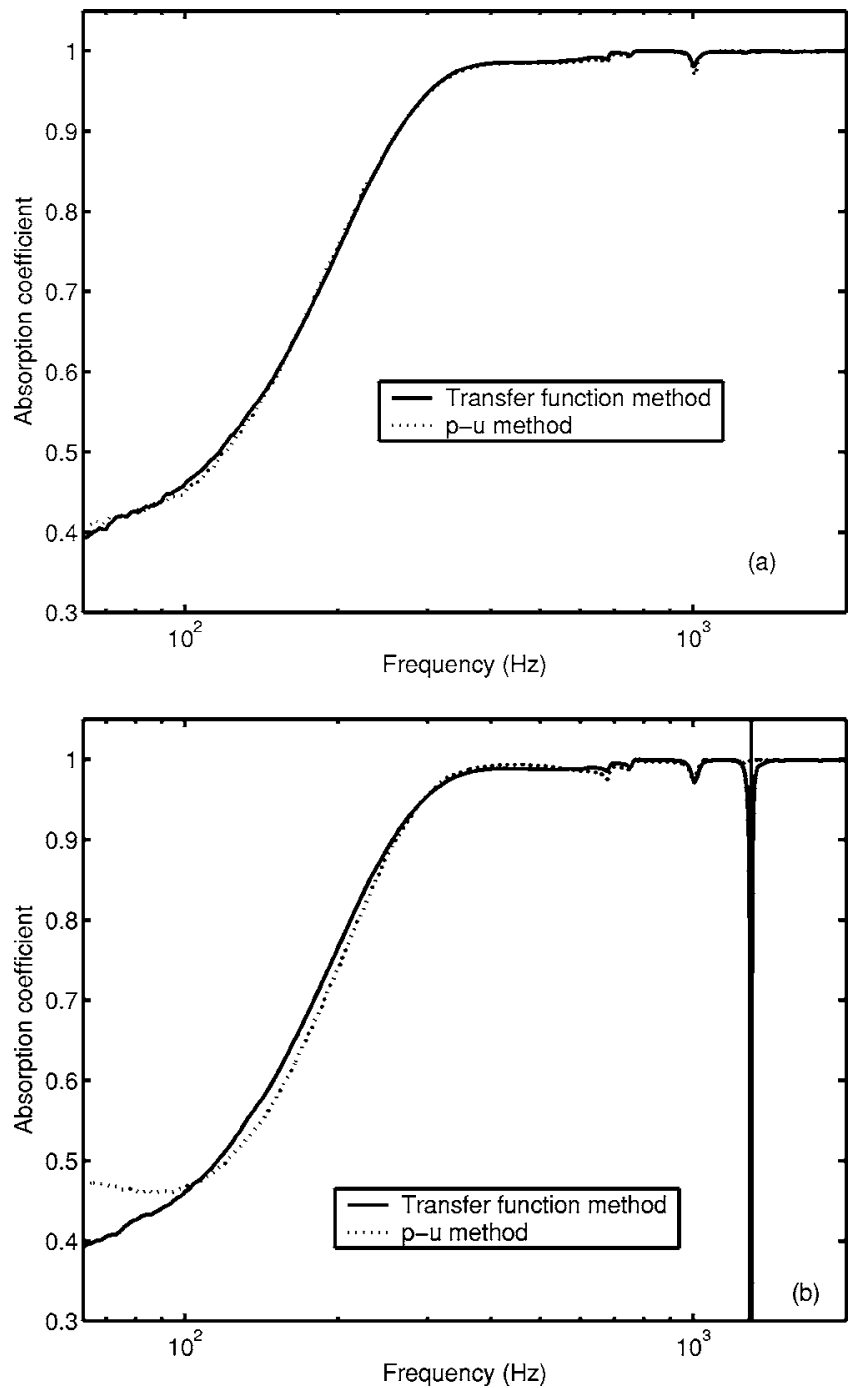

FIG. 3. Absorption coefficient of a wedge of mineral wool. Transducer positions (a) near the material, and (b) far from the material.

sure channel by exposing the devise to the sound field generated by a small loudspeaker at a distance of $4 \mathrm{~m}$ in DTU's large anechoic room. The calibration procedure has been described in Refs. 9 and 11.

Figures 3(a) and 3(b) show the results of the two methods with a highly absorbing termination of the tube, a $30-\mathrm{cm}$-long wedge of mineral wool terminated by a rigid cap, measured using different positions in the tube. It is apparent that the wedge absorbs sound very well from $200 \mathrm{~Hz}$ and upwards. The results shown in Fig. 3(a) have been determined with the Microflown probe in the hole nearest the absorbing material and with the two pressure microphones in the two holes nearest the material; the results shown in Fig. 3(b) have been determined with the Microflown probe $21 \mathrm{~cm}$ further from the material and with the two pressure microphones in the two holes furthest from the material. The two methods are in excellent agreement when the transducer positions closest to the material are used. The agreement is fair, but less perfect with the other positions. The sharp dip in the results of the transfer function method at $1.3 \mathrm{kHz}$ is due

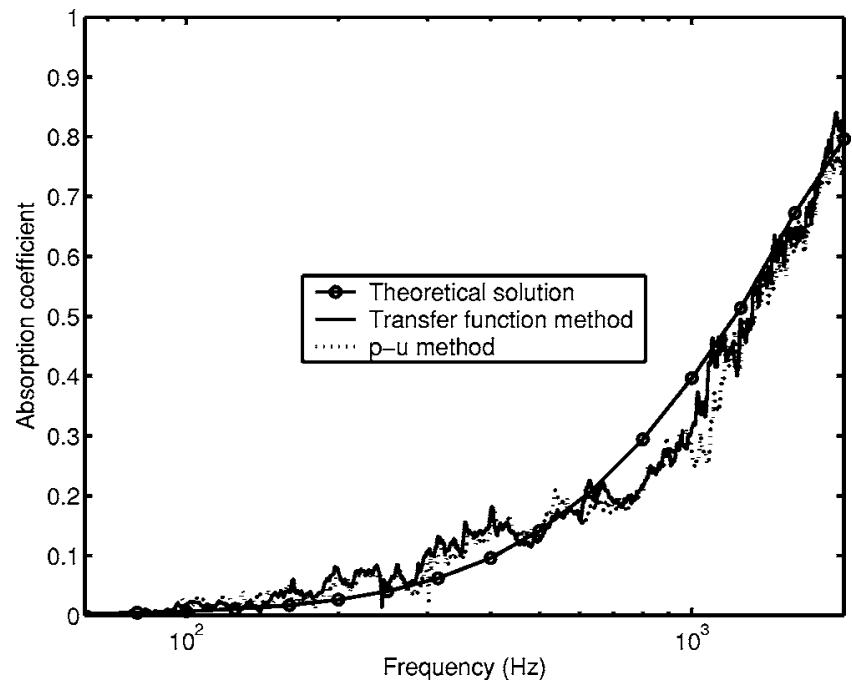

FIG. 4. Apparent absorption coefficient of the open tube.

to the distance between the microphones $(13 \mathrm{~cm})$ being half a wavelength - at this frequency Eq. (1) becomes indeterminate- but otherwise the transfer function method is not affected by the transducer positions. There is no obvious explanation for the small irregularities observed in all curves between $680 \mathrm{~Hz}$ and $1 \mathrm{kHz}$, but since all the measurements are in agreement the explanation may well be related with mechanical resonances.

Figure 4 shows the apparent absorption coefficient of the open tube, using the transducer positions closest to the opening. An open tube has the advantage that its reflection factor can be predicted theoretically, if only for an unflanged tube of circular cross section. ${ }^{12}$ At low frequencies the opening of the tube reflects sound strongly (in antiphase), but above $1 \mathrm{kHz}$ a significant fraction of the incident sound energy is "absorbed," that is, radiated. The two methods are in good agreement. The fluctuations of the two curves are mainly caused by background noise from outside of the tube. However, both curves differ somewhat from the theoretical solution, in all probability because the expression derived in Ref. 12 is for a tube of circular cross section.

The (small) deviations that have been observed between the absorption coefficient measured with the transfer function method and the absorption coefficient determined with the method based on measurement of sound pressure and particle velocity may well be due to imperfect calibration of the velocity transducer.

\section{CONCLUSION}

A method of measuring normal-incidence absorption coefficients with a sound intensity probe that provides the sound pressure and the particle velocity at the same position has been examined by comparing with the well-established transfer function method based on two pressure microphones in an impedance tube. The results, which also have implications for in situ measurements of the acoustic impedance of materials with $p-u$ probes, show that this method can be as accurate as the transfer function method. However, whereas 
the influence of transducer mismatch on the transfer function method can be eliminated with a simple sensor-switching technique there is no similar way of removing phase and amplitude mismatch between the two transducers of the $p-u$ probe; they must be calibrated within a tolerance of $0.5 \mathrm{~dB}$ and $2^{\circ}$.

\section{ACKNOWLEDGMENT}

The authors are indebted to Microflown Technologies BV for lending us a $p-u$ sound intensity probe.

${ }^{1}$ A. F. Seybert and D. F. Ross, "Experimental determination of acoustic properties using a two-microphone random-excitation technique," J. Acoust. Soc. Am. 61, 1362-1370 (1977).

${ }^{2}$ J. Y. Chung and D. A. Blaser, "Transfer function method of measuring in-duct acoustic properties. I. Theory," J. Acoust. Soc. Am. 68, 907-913 (1980).

${ }^{3}$ ISO 10534-1:1996, "Acoustics—Determination of sound absorption coefficient and impedance in impedance tubes-Part 1: Method using standing wave ratio."
${ }^{4}$ ISO 10534-2:1998, "Acoustics-Determination of sound absorption coefficient and impedance in impedance tubes-Part 2: Transfer-function method."

${ }^{5}$ A. F. Seybert and B. Soenarko, "Error analysis of spectral estimates with application to the measurement of acoustic parameters using random sound fields in ducts," J. Acoust. Soc. Am. 69, 1190-1199 (1981).

${ }^{6}$ H. Bodén and M. Åbom, "Influence of errors on the two-microphone method for measuring acoustic properties in ducts," J. Acoust. Soc. Am. 79, 541-549 (1986).

${ }^{7}$ H.-E. de Bree, "The Microflown: An acoustic particle velocity sensor," Acoust. Aust. 31, 91-94 (2003).

${ }^{8}$ R. Raangs, W. F. Druyvesteyn, and H.-E. de Bree, "A low-cost intensity probe," J. Audio Eng. Soc. 51, 344-357 (2003).

${ }^{9} \mathrm{~F}$. Jacobsen and H.-E. de Bree, "Measurement of sound intensity: $p-u$ probes versus $p$ - $p$ probes," Proceedings of Noise and Vibration Emerging Methods 2005, Saint Raphaël, France, 2005.

${ }^{10}$ A. Cummings, "Impedance tube measurements on porous media: The effect of air-gaps around the sample," J. Sound Vib. 151, 63-75 (1991).

${ }^{11}$ F. Jacobsen and H.-E. de Bree, "A comparison of two different sound intensity measurement systems," J. Acoust. Soc. Am. 118, 1510-1517 (2005).

${ }^{12}$ H. Levine and J. Schwinger, "On the radiation of sound from an unflanged circular pipe,” Phys. Rev. 73, 383-406 (1948). 